American Journal of Pharmaceutical Education 2019; 83 (2) Article 6505.

\title{
RESEARCH
}

\section{Using a Novel Student-centered Teaching Method to Improve Pharmacy Student Learning}

\author{
Xin Meng, PharmD ${ }^{\mathrm{a}}$, Lianrong Yang, PharmD ${ }^{\mathrm{a}}$, Hui Sun, PharmD ${ }^{\mathrm{a}}$, Xiaowei Du, PharmD ${ }^{\mathrm{a}}$, \\ Bingyou Yang, PharmD ${ }^{\mathrm{a}}$, Hongwei Guo, $\mathrm{PhD}^{\mathrm{a}}$ \\ ${ }^{a}$ School of Pharmacy, Heilongjiang University of Chinese Medicine, Harbin, China \\ Submitted May 4, 2017; accepted October 24, 2018; published March 2019.
}

\begin{abstract}
Objective. To improve students' learning and develop their learning skills in pharmacy education. Methods. A novel teaching method composed of Self-study, Test, Question and Discussion (STQD) sessions uses self-, peer-, co-learning, active learning, inductive teaching, and formative assessment to promote student-centered teaching in pharmacy education. STQD has been implemented within courses focusing on instrumental analysis and analytical chemistry. In a four-year study, qualitative and quantitative approaches were used to evaluate the effectiveness of STQD in facilitating students' learning.

Results. Students positively evaluated their experience in STQD class with an overall mean and standard deviation of $4.35(0.64)$ in a 5-point Likert scale, where a score of 1 is "strongly disagree" and a score of 5 is "strongly agree." The final examination results showed students' average score in an STQD class was higher than students' average score in a traditional class. Most students indicated that the STQD improved their learning ability, communication ability and facilitated their learning.

Conclusion. The use of STQD in an integrated basic science curriculum has the potential to develop students' learning skills and improve their learning in pharmacy education.
\end{abstract}

Keywords: pharmacy education, student-centered teaching, formative assessment, active learning, inductive teaching

\section{INTRODUCTION}

Lecture-based learning, a teacher-centered traditional pedagogy, is the most common teaching method in pharmacy education around the world. ${ }^{1-3}$ In pharmaceutical courses, the traditional teaching methods consist of lectures and direct instructions conducted by teachers. Students are expected to listen to lectures and learn from teachers instead of encouraging them to interact and take the initiative to analyze problems. ${ }^{4,5}$ Most pharmaceutical basic science courses involve rote learning, in which students depend on memorization without having a complete understanding of the subject. Students complete the curriculum by passing the tests, consisting of descriptions, matching and other forms of indicators. Little or no attention is paid to what practical problems students can solve with the knowledge they have learned. Long lectures and little interaction in traditional pharmacy education often leave students less attentive and engage with low retention. ${ }^{6,7}$ However, there are various methods

Corresponding Author: Xin Meng, School of Pharmacy, Heilongjiang University of Chinese Medicine. 24 Heping Rd., Harbin 150040, China. Tel: +86-045187267040. Fax: +86045182193000. E-mail: mengxin52309@163.com a student can engage that will allow them to learn at different rates of retention. Dale's study illustrated the percentage of learner recall that was associated with various approaches. ${ }^{8,9}$ Lectures, reading, audiovisuals and demonstrations are passive learning methods. In contrast, discussion groups, practice by doing and teaching others are active learning methods. The active participation in the learning process results in a higher retention of learning. When students are actively involved and collaborate with others, their retention rate dramatically increases. ${ }^{10-}$ 13 Therefore, it is best to design lessons and activities using active learning methods to ensure learners are actively engaged in the learning process.

Many pharmacy schools and colleges have introduced innovative web-, problem-, project-, case-, and game-based strategies to improve students' learning. ${ }^{14-16}$ In most cases, there is an explicit need to choose instructional approaches that promote student-centered teaching. Student-centered teaching has repeatedly been shown to be superior to the traditional teacher-centered approach to instruction because it allows students to solve problems, cooperative learning, and inductive learning. ${ }^{17-20}$ Inductive teaching is an effective method of linking theory with practice and involves 


\section{American Journal of Pharmaceutical Education 2019; 83 (2) Article 6505.}

students discussing questions and solving problems in class, with much of the work in and out of class being done by students learning in groups. ${ }^{21,22}$ Student-centered teaching methods include active learning, which involves students participating in all three phases of the learning process (input, operations, and feedback). ${ }^{23}$ This type of learning is more apt to stimulate critical thinking, taking levels of individual students into consideration to enable development of their learning ability and investigative skills. ${ }^{24}$ From 2013 to 2016, a novel student-centered teaching method named Selfstudy, Test, Question and Discussion (STQD) was designed and implemented within courses focusing on instrumental analysis and analytical chemistry. Self-, peer-, co-learning, active learning, inductive teaching, and formative assessment were used to promote student-centered teaching in pharmacy education.

The objectives of this study were to improve students' learning and develop their learning skills in pharmacy education.

\section{METHODS}

From 2013 to 2016, there were 60 students enrolled each year in the pharmacy program at Heilongjiang University of Chinese Medicine. Among the 60 students, 30 were randomly assigned to the experimental class (intervention group), while the other 30 were assigned to the traditional class (control group) (Table 1). All students voluntarily agreed to participate in the study. This study was approved by the Heilongjiang University of Chinese Medicine Review Board and Ethics Committee.

At Heilongjiang University of Chinese Medicine, the undergraduate pharmacy education program is a fouryear program in which basic science instruction is delivered in the first two years followed by professional

Table 1. Demographic Data of the Experimental Class vs Traditional Class

\begin{tabular}{cccc}
\hline $\begin{array}{c}\text { Evaluation } \\
\text { Categories }\end{array}$ & $\begin{array}{c}\text { Sub- } \\
\text { categories }\end{array}$ & $\begin{array}{c}\text { Novel Teaching } \\
\text { Method Class } \\
\text { N=120 }\end{array}$ & $\begin{array}{c}\text { Traditional } \\
\text { Class N=134 }\end{array}$ \\
\hline Number of & 2013 & 30 & 32 \\
students & 2014 & 30 & 34 \\
& 2015 & 30 & 35 \\
& 2016 & 30 & 33 \\
Gender & Male & 39 & 46 \\
Age & Female & 81 & 88 \\
& $18-19$ & 35 & 40 \\
College & $20-21$ & 79 & 86 \\
entrance & $541-580$ & 6 & 14 \\
scores & $581-620$ & 12 & 107 \\
\hline
\end{tabular}

courses in the third and fourth years. Lecture-based learning was used in the traditional class while STQD was used in the experimental class. Students were provided selflearning materials and feedback to guide them in their self-study. STQD was implemented in two different subjects, instrumental analysis and analytical chemistry. Qualitative and quantitative approaches were used to evaluate the effectiveness of STQD in facilitating student learning. Figure 1 shows a schematic illustration of STQD.

Before the first class, the experimental class students completed the Catell 16 Personality Factor Questionnaire. At the time of grouping, the results of Primary Factor Warmth (Factor A) in the Catell questionnaire were used to determine whether a student was introverted or extroverted. Students may also inform the instructors whom they would like to study with. The students were divided into learning groups based on their college entrance scores, personality, interpersonal relationship and classmates they'd like to study with. Each group was composed of students who had different college entrance scores (high, medium and low scores) and different personalities (introverted and extroverted). Each group chose and took turns to be a leader for each lesson. Each semester, the students were re-grouped based on their last semester scores, personality and wishes with whom they'd like to study with. Re-grouping created a new grouplearning environment and allowed students to play different roles in the new group.

Two days before each lesson in the experimental class, the teacher marked the scope of study, key points and difficulties. Animation courseware, video, academic paper were created into web pages for student self-study. Students could preview and review the materials by themselves. There was no time limit in the self-study process. Students could discuss questions and problems with their groupmates. If the problem was still not resolved, it would be discussed in class. Each student prepared three questions for class discussion.

Formative assessment was used in STQD. At the beginning of each class, there was a 5- to 10-minute test to evaluate student learning. Students received their test results for their self-assessment at the beginning of the next lesson. The STQD feedback, a central function of the formative assessment, focused on the detailed content of what was being learnt, rather than simply a test score or other measurement of how far a student was not meeting the expected standard. Students received feedback, including which areas they need to improve and how they could improve. Based on the feedback, students could adjust their learning strategies to improve their grades in the experimental class. 


\section{American Journal of Pharmaceutical Education 2019; 83 (2) Article 6505.}

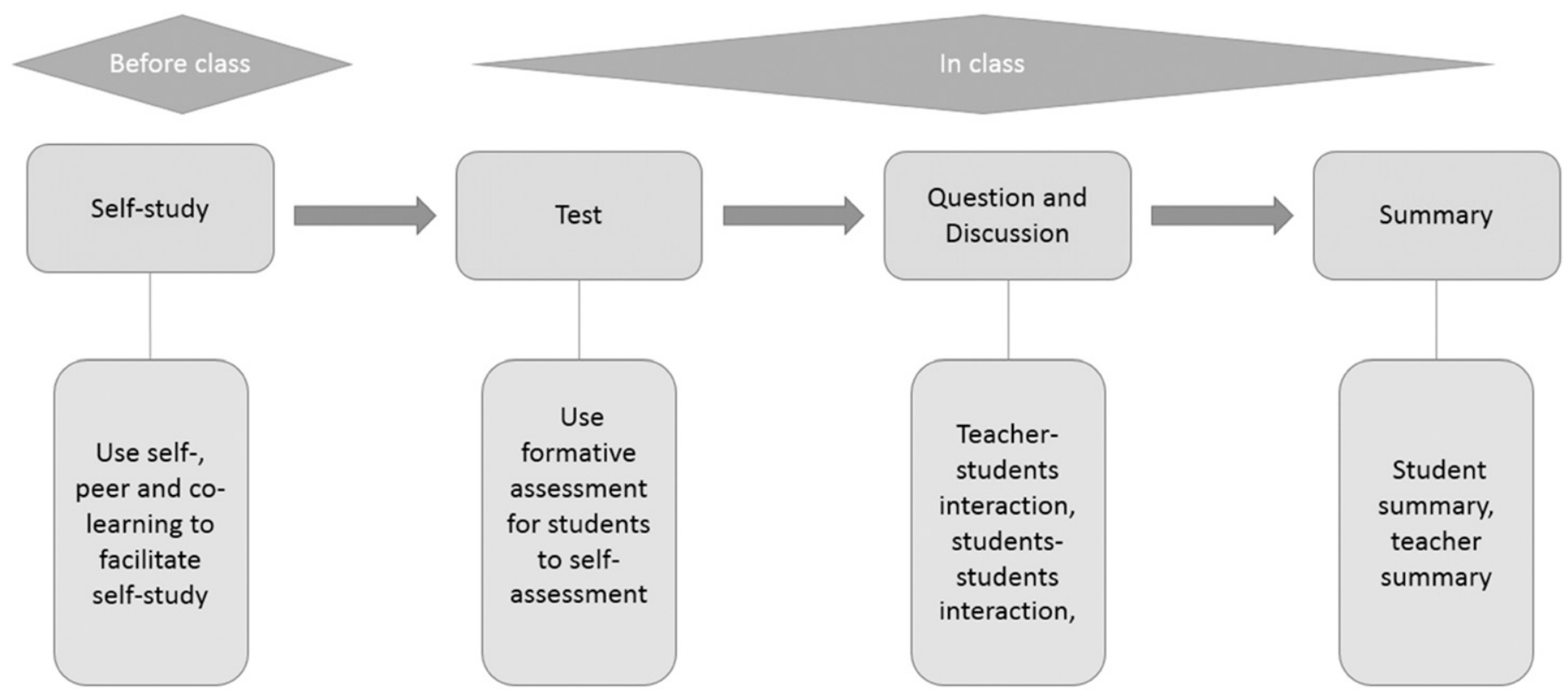

Figure 1. Schematic Illustration of the Novel Student-centered Teaching Method

There was a 10 - to 15 -minute introduction to the lesson and the frontiers in the field to broaden students' knowledge and to introduce them to practical problems that could be solved by what they have learned. This was followed by a question and discussion session in which inductive teaching was used. During this session, students raised the problems they encountered during their selfstudy and remained unsolved during their group discussion. Groups had 1-2 minutes to discuss and solve the problem. If the students answered correctly, they received points. If no student could solve the problem, the teacher would solve the problem. STQD could improve classroom teaching efficiency by allowing the teacher to focus on solving the problems that students could not solve by themselves. The teacher does not have to teach students what they had mastered in self-study. This method encouraged students to think actively about their peers' problems, which perhaps they did not find in self-study.

Problem situations, designed by teachers, were given to each student. After a 5-minute discussion, the teacher would randomly choose a student to answer on behalf of the group to ensure that each member of the group formed a consistent answer by communication and learning from each other. It is important for the teacher to randomly choose a student to answer, so that all students would be prepared. If the group representative answered correctly, the group would receive points. If the group representative gave the wrong answer, the other members of the group could answer on behalf of the group. If the answer was correct, the group would be rewarded with half of the original points. If no group member could answer, the teacher would choose another group representative to answer. To be fair, teachers should give equal chances for each group.

The teacher randomly selects students to raise questions prepared before class. After a 5-minute discussion, the teacher selects a student to answer the question posed by the other students. If the student answers correctly, he or she would receive points. In the first and third parts of the question and discussion session, most of the time, the teacher would call on the student who raised his or her hand first. Sometimes the teacher would also let several students answer a question, with each student answering a part of the question. Although this approach may leave some students with a negative experience if they were not selected, the teacher gives every student an opportunity to answer a question in class as often as possible. This is also a potential area of improvement that needs to be researched using novel educational technologies. For example, smartphone applications can be used for student participation. The point-awarding system, a formative assessment, encouraged students to learn and improve performance because they were in competition with their peers. In this session, students would take the initiative to think and learn by looking for problems, preparing and answering questions. This practice could improve the breadth, depth and retention of student knowledge.

There was a summary session at the end of each class wherein the students summarized what they learned. The teacher would randomly choose a group, and then the group would choose a member to summarize the lesson and assess the performance of each group including theirs. At the end, the teacher would give a summary of the lesson. 


\section{American Journal of Pharmaceutical Education 2019; 83 (2) Article 6505.}

After class, feedback would be sent to every student by email. The feedback consisted of five sections: the classroom performance of the student, class scores, advantages, disadvantages, how to improve. Students would also provide their own self-assessment, group assessment and suggestions to the teacher by email.

In a traditional class, lecture-based learning is used where the teacher would give a lecture while the students listened and took notes. At the end of each class, the teacher would give homework. Deductive teaching and summative assessment were used in the traditional class. Both cohorts participated in the same final examination to assess the retention of basic science knowledge.

Questionnaires with closed- and open-ended items were designed to determine student perceptions. A 5point Likert scale, where 1 was strongly disagree and 5 was strongly agree, was used to quantify responses in the closed-ended items. There were two kinds of questionnaires; a non-STQD-related and a STQD-related. The questionnaires had been piloted in 15 STQD students and 15 traditional class students.

In non-STQD-related questionnaire, closed-ended questions were grouped into three categories: learning process, skill development and learning enthusiasm. The non-STQD-related questionnaire was administered in both cohorts. The STQD-related questionnaire, including closed- and open-ended question items, was designed to collect opinions and perceptions on the effectiveness of the STQD in improving basic science learning, to identify the preferred elements of the STQD, and to collect students' suggestions for improving the STQD. The STQDrelated questionnaire was only administered in STQD class. Both STQD-related questionnaire and nonSTQD-related questionnaire were administered during the week after the midterm examination. After the midterm examination, students evaluated the teaching method and made recommendations.

Demographic data was analyzed to identify general characteristics of the student participants. All statistical analyses were performed using IBM SPSS 19.0 Statistics (Armonk, NY). For continuous variables with distributions that approximated normality, $t$-test was used for comparisons between the two groups. When normality assumptions were not satisfied, the nonparametric Mann-Whitney U test was used. All data were expressed as mean and standard deviation of each parameter.

\section{RESULTS}

The response rates in non-STQD-related questionnaire survey were $97 \%(116 / 120$ the experimental class students) and 96\% (129/134 the traditional class students). The response rate in STQD-related questionnaire survey was $97 \%(116 / 120$ the experimental class students). Because the annual sample size was small, the response rates were high. Table 1 shows the demographic data of both cohorts. In the four-year study, there were 120 students in the experimental class, and 134 students in the traditional class. The proportions of gender, age and college entrance scores of the students in the experimental class were the same as that of students in the traditional class.

The results of the questionnaire showed strong acceptance and positive attitudes toward the utilization of STQD to facilitate learning of basic science in pharmacy education. Students positively evaluated their experience using the STQD with an overall mean score 4.35 (SD 0.64 ). High ratings were received for the different evaluation categories that were used to assess the effectiveness of the STQD. Students perceived that the use of graphics and animations stimulated their interest and enhanced their learning process. They believed that the STQD provided the basic knowledge needed to prepare for in-class discussion, the test had played a role in supervising the extracurricular self-study, the mode of classroom discussion and group competition stimulated their enthusiasm for active learning.

Table 2 provides examples of student responses on each of the themes in non-STQD-related questionnaires. Results of non-STQD-related questionnaire showed both STQD and traditional teaching methods could improve student core knowledge. Compared with the traditional class, students in the experimental class were more willing to learn and spend more time preparing for lessons. Both teaching methods could improve research and judgment skills. The traditional class students believed that traditional teaching method failed to improve their ability to solve problems, while the experimental class students believed the new teaching method could improve their problem-solving ability. The results of the survey showed that STQD had more advantages in developing students' multiple skills than the traditional method. There was a significant difference $(p<.01)$ when comparing satisfaction between the two cohorts, indicating students in the experimental class were more satisfied with basic science learning.

All participants who responded to the items in the open-ended questionnaire in the experimental class agreed that STQD was effective in improving their learning and provided responses describing how STQD improved their learning.

Table 3 provides examples of student responses on each of the themes in STQD-related questionnaire. The students indicated that the web-based self-study and extracurricular group discussion in the STQD helped to 


\section{American Journal of Pharmaceutical Education 2019; 83 (2) Article 6505.}

Table 2. Results of Non-Novel Teaching Method-related Questionnaires from the Experimental Class and the Traditional Class

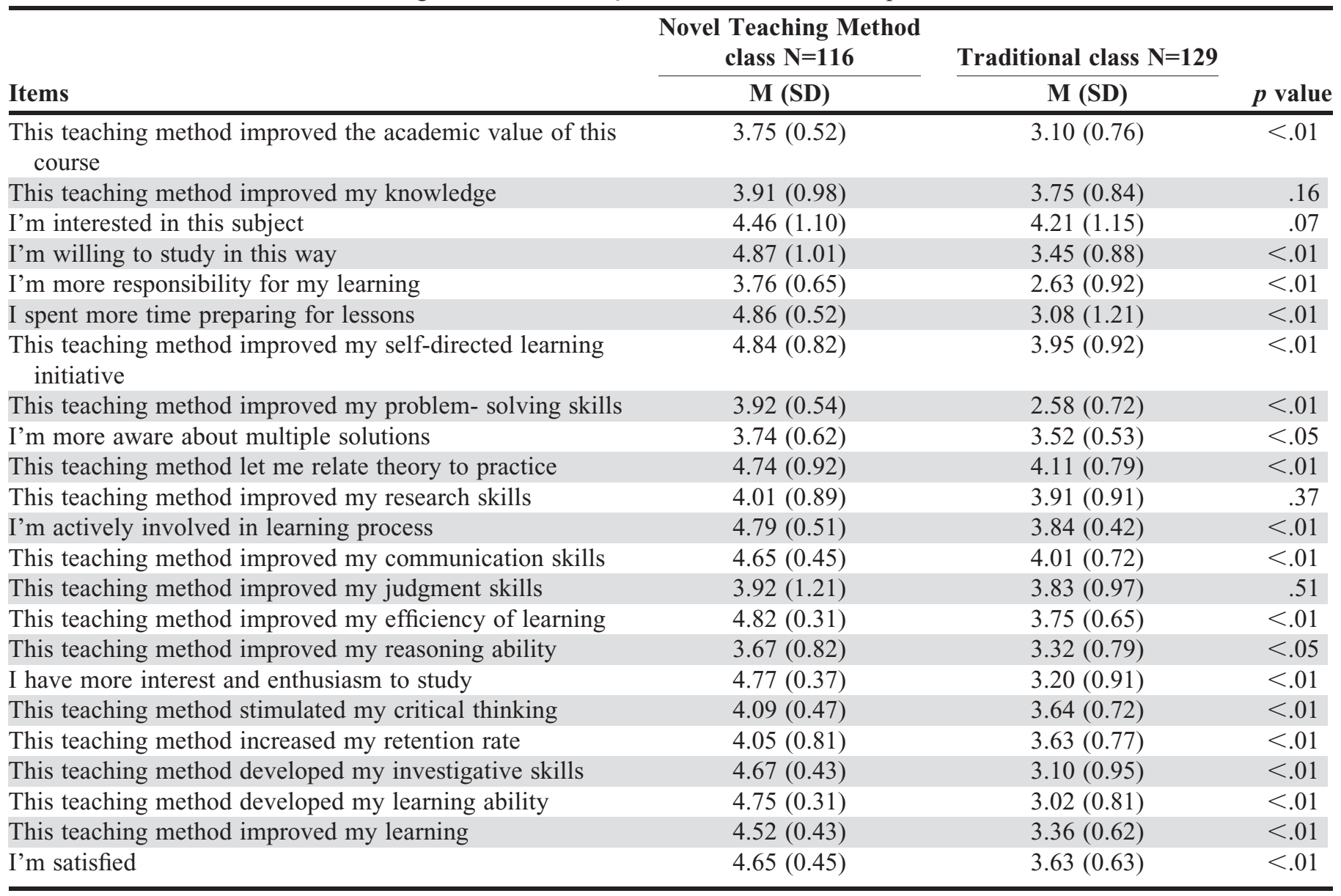

understand concepts with a mean score of 4.05 (SD 0.91). Eighty-eight percent of the students strongly agreed that the self-study session of STQD was beneficial. Furthermore, $95 \%$ of the students strongly agreed that the selfstudy session of STQD was better than traditional method. The results of the open-ended questionnaire showed students found the self-study session of STQD to be effective in improving retention of basic science information (Table 4). This new model enabled students to do their own learning and could significantly improve knowledge retention.

As shown in Table 3, the test session could help students to prepare for in-class discussion with a mean score of 4.02 (SD 0.62). A qualitative analysis of student responses to open-ended items on the questionnaire found that the test session made them more motivated to take the initiative to learn and could help them with selfassessment. The experimental class students pointed out

Table 3. Results of the Novel Teaching Method-related Questionnaires from the Experimental Class $(\mathrm{N}=116)$

\begin{tabular}{ll}
\hline Evaluation Categories & M (SD) \\
\hline Web-based self-study improved learning efficiency & $4.46(1.10)$ \\
Graphics and animations in self-study session stimulated interest & $4.21(0.98)$ \\
Group discussion at the self-study stage helped to understand concepts & $4.05(0.91)$ \\
The self-study session of the novel teaching method was beneficial & $4.73(0.64)$ \\
The self-study session of the novel teaching method was better than traditional method & $4.92(0.59)$ \\
The test session helped to prepare for in-class discussion & $4.02(0.62)$ \\
The questions and discussions session promote the communication between students and teachers & $4.85(0.41)$ \\
The discussion stimulated active learning & $4.54(0.70)$ \\
The point-awarding system made me more enthusiastic to learn & $4.62(0.51)$ \\
Feedback improved my learning & $4.51(0.66)$
\end{tabular}




\section{American Journal of Pharmaceutical Education 2019; 83 (2) Article 6505.}

Table 4. Experimental Class Students' Responses to Open-ended Questions (N=116)

\begin{tabular}{|c|c|}
\hline Themes & Example of student's response \\
\hline Self-study session & $\begin{array}{l}\text { "I like this session. The graphics and animations in the self-study session stimulated my } \\
\text { interest and enhanced my learning process. It was time efficient and effective in improving } \\
\text { my knowledge retention." }\end{array}$ \\
\hline Test session & $\begin{array}{l}\text { "The Test session made me more motivated to take the initiative to learn and could help me self- } \\
\text { assessment. Although the test session made me a little nervous, it really promoted my study." }\end{array}$ \\
\hline $\begin{array}{l}\text { Question and Discussion } \\
\text { session }\end{array}$ & $\begin{array}{l}\text { "I learned more in the course of the discussion. The mode of classroom discussion and group } \\
\text { competition stimulated my enthusiasm for active learning." }\end{array}$ \\
\hline Feedback session & "The feedback from the test session was very helpful to improve my learning." \\
\hline Point-awarding system & $\begin{array}{l}\text { "The point-awarding system made my study more passionate and I would study harder in order to } \\
\text { get points. Although sometimes I was a little disappointed when I did not get points, I would } \\
\text { study harder to get more points next time. In a word, this point-awarding system promoted my } \\
\text { learning." }\end{array}$ \\
\hline $\begin{array}{l}\text { The novel teaching } \\
\text { method }\end{array}$ & $\begin{array}{l}\text { "I really like this way of teaching. It is very interesting. The knowledge expansion and our } \\
\text { collaborative spirit could be developed in this way." }\end{array}$ \\
\hline
\end{tabular}

that the feedback from the test session was helpful in improving their learning. Although a few students wrote that the test session made them nervous, they agreed that it promoted their study.

Students agreed that the question and discussion session could promote communication between students and teachers with mean score of 4.85 (SD 0.41). Survey results showed that when students were answering questions on behalf of the group, they were inclined to perform better so that they would learn harder. When students prepared classroom questions and answers, they consciously read more learning materials and had a deeper understanding the lesson. In the open-ended questionnaire, some students wrote that the active learning, knowledge expansion, distinctive mind and collaborative spirit could be developed in this way. Based on feedback about STQD, it improved student learning with a mean score of 4.51 (SD 0.66).

Analysis of the final examination indicated a significant difference $(p<.05)$ in students' performance between STQD class (mean 85, SD 15, $\mathrm{n}=120$ ) and traditional class (mean 74 , SD 18, $\mathrm{n}=134$ ) in a four-year study.

\section{DISCUSSION}

STQD used multiple existing teaching methodologies for independent and active learning to develop learning skills and improve outcomes in pharmacy education. The main reason for the positive outcomes was an effective combination of self-study, test, discussion, feedback, point-awarding system.

Grouping was an important step in STQD, whose method was carefully designed. In the early days of this study, students were grouped randomly or voluntarily. When all the students in one group were introverted, it was difficult for the group to complete the discussion, and most of the group members would learn from themselves; while the discussion became too intense when all group members were extroverted. ${ }^{25}$ It was also a problem when all students tended to study with high achieving students in one group. ${ }^{26,27}$ To better learn from each other, discuss within and between groups, and compete, the grouping method was carefully designed as described in the method section.

The self-study session of STQD positively affected student motivation and supported the development of self-regulatory skills. There was no time control in the self-study process, so students could study and discuss at their own pace, which may have a positive effect on students who were tasked with learning core materials ahead of classes. ${ }^{28}$ Students would take the initiative to spend more time on issues that they felt were difficult and less time on simple issues. Web-based self-study helped to engage the learners in active processing of instructional materials to increase interest in learning. ${ }^{29}$ Previous studies demonstrated that visuals had positive effects on facilitating student achievement. ${ }^{30-32}$ Students could select the pace and type of interactivity based on their current knowledge. Educational animations supported conceptualization and contextualization of instructional materials, and promoted internal reflection for deeper understanding. ${ }^{33}$

Formative assessment in STQD represents an educational intervention that is consistent with the current emphasis on using assessment to improve student performance in pharmacy education. ${ }^{34,35}$ The formative assessment of STQD has four main stages: learning activities, assessment, feedback, and improvement. The test session as a part of formative assessment in STQD had indirect and direct benefits to student learning, which 


\section{American Journal of Pharmaceutical Education 2019; 83 (2) Article 6505.}

improved student knowledge retention after self-study and helped them self-assess and find deficiencies to improve their learning strategies. ${ }^{36-38}$ Believing in student ability to learn, emphasizing progress toward learning goals rather than score, and assessing the development of learning ability were all manners in which motivation was enhanced through an effective use of formative assessment in STQD. ${ }^{39}$

Inductive teaching in STQD could be characterized as a constructivist method in which students construct their own knowledge rather than the teacher imparting it to them. ${ }^{40,41}$ In class, the discussion provided opportunities for knowledge elaboration. ${ }^{42}$ When students were able to answer their classmates' questions from their self-study, they gained a higher sense of achievement and increased their motivation to learn. ${ }^{26,43,44}$ The use of a point-awarding system played a vital role in the success of the teaching strategy because students were encouraged to learn, and improve their performance because they were competing with their peers. Because the teacher randomly chose a student to answer on behalf of the group, students studied harder. Aside from group competition, there was also individual competition. Because each student could gain an individual point, student scores were also different from each other within the group. In STQD, it is essential to create effective classroom discussions, allow students to become instructional resources for each other, and stimulate students to become owners of their own learning. Because of classroom discussions and the point-awarding system, students took the initiative to spend more time preparing for lessons outside the classroom.

In lecture-based class, deductive teaching is the teaching method is used. The instructor conducts lessons by introducing and explaining concepts or skills to the students, then students practice the skills they were taught. This is a teacher-centered model of teaching that is rule driven. Some of the positives of this method include: it is easy to get the main points of the lesson and it is suitable for teaching a large class. ${ }^{45}$, However, the classroom teaching efficiency of this method was lower than that of STQD. In this study, the students in the experimental class not only completed the same content in fewer lessons, especially without time control in the self-study session, but also showed better performance and more satisfaction. STQD could increase the time for students to learn outside the classroom independently and improve classroom teaching efficiency. The result of the final examination indicated that, compared with the traditional teaching method, STQD could also improve knowledge retention.
This study outlined several effective design strategies that should be considered when developing STQD. The essential elements of the STQD include effective self-study, test, feedback, question and discussion. Using STQD to encourage self-directed learning is consistent with the goal of developing the skills for lifelong learning in pharmacy education. Although STQD is successful in basic course, it applies only to small classes of fewer than 30 students. This study focused on this method only in the basic science curriculum in pharmacy education. Future research should focus on the application of STQD in other subjects.

\section{CONCLUSION}

Assessment data support that STQD is an effective student-centered teaching method, in which students formulate questions of their own, solve problems, discuss, explain, debate during class. The use of STQD in an integrated basic science curriculum has the potential to develop students' learning skills and improve their learning of basic sciences in pharmacy education. The utilization of STQD in pharmacy education has the potential for individualized teaching. When implementing STQD, it is necessary to understand each student as much as possible to make a reasonable grouping. Controlling the rhythm of classroom discussion is crucial in STQD. The self-learning materials and feedback provided to the students will increase teachers' workload. Future research should focus on the application of STQD in other subjects of pharmacy education.

\section{ACKNOWLEDGMENTS}

This work was supported by Heilongjiang Province Education Science "13th Five-Year" Youth Fund Project Planning (No. GJD1316033), Heilongjiang Province Higher Education Society "13th Five-Year" Higher Education Research Project Fund (No. 16Q265), and Heilongjiang University of Chinese Medicine Education Research Fund (No. XJJ2015014).

\section{REFERENCES}

1. Islam MA, Khan SA, Talukder RM. Status of physiology education in US Doctor of Pharmacy programs. Adv Physiol Educ. 2016;40(4):501-508.

2. Steeb DR, Overman RA, Sleath BL, Joyner PU. Global experiential and didactic education opportunities at US colleges and schools of pharmacy. Am J Pharm Educ. 2016;80(1):Article 7. 3. Knoer SJ, Eck AR, Lucas AJ. A review of American pharmacy: education, training, technology, and practice. J Pharm Health Care Sci. 2016;2:32.

4. Bertran S, Boby H, Bertrand PM, Pereira B, Perbet S, Lautrette A. Comparison of video-based learning and lecture-based learning for training of ultrasound-guided central venous catheterization: a 


\section{American Journal of Pharmaceutical Education 2019; 83 (2) Article 6505.}

randomized controlled trial. Brit J Anaesthesia. 2017;118(4):628630 .

5. Lucieer SM, van der Geest JN, Eloi-Santos SM, et al. The development of self-regulated learning during the pre-clinical stage of medical school: a comparison between a lecture-based and a problem-based curriculum. Adv Health Sci Educ Theory Pract. 2016;21(1):93-104.

6. Nazar H, Obara I, Paterson A, Nazar Z, Portlock J, Husband A. A consensus approach to investigate undergraduate pharmacy students' experience of interprofessional education. Am J Pharm Educ.

2017;81(2):Article 26.

7. Shelvey BM, Coulman SA, John DN. Evaluating an undergraduate interprofessional education session for medical and pharmacy undergraduates on therapeutics and prescribing: the medical student perspective. Adv Med Educ Pract. 2016;7:661-670. 8. Fisher GS. Successful educational strategies and the pyramid of occupational therapy learning. Occup Ther Health Care. 2000; 12(1):33-45.

9. Masters K. Edgar Dale's pyramid of learning in medical education: a literature review. Med Teach. 35(11):e1584-e1593. 10. Pedrami F, Asenso P, Devi S. Using text analytics of AJPE article titles to reveal trends in pharmacy education over the past two decades. Am J Pharm Educ. 2016;80(6):Article 104.

11. Phelps A, Fritchle A, Hoffman H. Passive vs. active virtual reality learning: the effects on short- and long-term memory of anatomical structures. Stud health Technol Inform. 2004;98:298300 .

12. Willett LR. Comparing active and passive learning: what does the evidence really say? Acad Med. 2017;92(5):573.

13. Armstrong P, Elliott T, Ronald J, Paterson B. Comparison of traditional and interactive teaching methods in a UK emergency department. Eur J Emerg Med. 2009;16(6):327-329.

14. Devabhakthuni S, Reed BN, Watson K. Interactive Web-based regional journal club for postgraduate year 2 pharmacy residents in cardiology. Am J Health Syst Pharm. 2016;73(17):1300.

15. Isaacs AN, Walton AM, Nisly SA. Interactive web-based learning modules prior to general medicine advanced pharmacy practice experiences. Am J Pharm Educ. 2015;79(3):Article 40. 16. Bond SE, Crowther SP, Adhikari S, et al. Design and implementation of a novel Web-based e-learning tool for education of health professionals on the antibiotic vancomycin. $J$ Med Internet Res. 2017;19(3):e93.

17. Ross JG, Bruderle E. Effects of active, student-centered teaching strategies on nursing students' knowledge, skills, attitudes, and comfort related to patient safety. Nurse Educ. 2018;43(1):2-3. 18. Tricio JA, Montt JE, Ormeno AP, Del Real AJ, Naranjo CA. Impact of faculty development workshops in student-centered teaching methodologies on faculty members' teaching and their students' perceptions. J Dent Educ. 2017;81(6):675-84.

19. Goodman BE. An evolution in student-centered teaching. $A d v$ Physiol Educ. 2016;40(3):278-282.

20. Rezende-Filho FM, da Fonseca LJ, Nunes-Souza V, Guedes Gda S, Rabelo LA. A student-centered approach for developing active learning: the construction of physical models as a teaching tool in medical physiology. BMC Med Educ. 2014;14:189.

21. Hermann GD, Hincksman NG. Inductive versus deductive approaches in teaching a lesson in chemistry. Journal of Research in Science Teaching Volume 15, Issue 1. J Res Sci Teach. 1978; 15(1):37-42.

22. Karlins M, Schroder HM. Discovery learning, creativity, and the inductive teaching program. Psychol Rep. 1967;20(3):867-876.
23. De Lorenzo RA, Abbott CA. Effectiveness of an adult-learning, self-directed model compared with traditional lecture-based teaching methods in out-of-hospital training. Acad Emerg Med. 2004;

11(1):33-37.

24. Cleveland LM, Olimpo JT, DeChenne-Peters SE.

Investigating the relationship between instructors' use of activelearning strategies and students' conceptual understanding and affective changes in introductory biology: a comparison of two active-learning environments. CBE Life Sci Educ. Summer 2017;16(2).

25. Morgenstern FS, Hodgson RJ, Law J. Work efficiency and personality: a comparison of introverted and extraverted subjects exposed to conditions of distraction and distortion of stimulus in a learning task. Ergonomics. 1974;17(2):211-220.

26. Johnson JF, Bell E, Bottenberg M, et al. A multiyear analysis of team-based learning in a pharmacotherapeutics course. Am J Pharm Educ. 2014;78(7):Article 142.

27. Obad AS, Peeran AA, Shareef MA, et al. Assessment of firstyear medical students' perceptions of teaching and learning through team-based learning sessions. Adv Physiol Educ. 2016;40(4):536542 .

28. Musal B, Gursel Y, Taskiran HC, Ozan S, Tuna A. Perceptions of first and third year medical students on self-study and reporting processes of problem-based learning. BMC Med Educ. 2004;4:16. 29. Maki RH, Maki WS, Patterson M, Whittaker PD. Evaluation of a Web-based introductory psychology course: I. Learning and satisfaction in online versus lecture courses. Behav Res Meth Instruments Comp. 2000;32(2):230-239.

30. Fingeret AL, Martinez RH, Hsieh C, Downey P, Nowygrod R. Watch what happens: using a web-based multimedia platform to enhance intraoperative learning and development of clinical reasoning. Amer J Surg. 2016;211(2):384-389.

31. Pedwell RK, Hardy JA, Rowland SL. Effective visual design and communication practices for research posters: exemplars based on the theory and practice of multimedia learning and rhetoric. Biochem Mol Biol Educ. 2017;45(3):249-261.

32. Valizadeh S, Feizalahzadeh H, Avari M, Virani F. Effect of education of principles of drug prescription and calculation through lecture and designed multimedia software on nursing students' learning outcomes. Electron Physician. 2016;8(7):2691-2699. 33. Khalil MK, Nelson LD, Kibble JD. The use of self-learning modules to facilitate learning of basic science concepts in an integrated medical curriculum. Anat Sci Educ. 2010;3(5):219-226. 34. Fjortoft N. Self-assessment in pharmacy education. Am J Pharm Educ. 2006;70(3):Article 64.

35. Remsberg CM, Bray BS, Wright SK, et al. Design, implementation, and assessment approaches within a pharmacogenomics course. Am J Pharm Educ. 2017;81(1):Article 11. 36. Hill DA, Guinea AI, McCarthy WH. Formative assessment: a student perspective. Medical Educ. 1994;28(5):394-399.

37. Arnold KM, McDermott KB. Test-potentiated learning: distinguishing between direct and indirect effects of tests. $J$ Exp Psychol Learn Mem Cogn. 2013;39(3):940-945.

38. Frame TR, Cailor SM, Gryka RJ, Chen AM, Kiersma ME, Sheppard L. Student perceptions of team-based learning vs traditional lecture-based learning. Am J Pharma Educ. 2015;79(4):Article 51. 39. Lutze-Mann L, Kumar RK. The formative assessment lecture: enhancing student engagement. Med Educ. 2013;47(5):526-527. 40. Jones VS, Holland AJ, Oldmeadow W. Inductive teaching method-an alternate method for small group learning. Med Teach. 2008;30(8):e246-e249. 


\section{American Journal of Pharmaceutical Education 2019; 83 (2) Article 6505.}

41. Prince MJ, Felder RM. Inductive teaching and learning methods definitions, comparisons, and research bases. Journal of Engineering Education Volume 95, Issue 2. Res J Eng Educ. 2006;95(2):123-138. 42. Stenlund T, Jonsson FU, Jonsson B. Group discussions and testenhanced learning: individual learning outcomes and personality characteristics. Educ Psychol. 2017;37(2):145-156.

43. Iwata K, Doi A. Can hybrid educational activities of team and problem based learning program be effective for Japanese medical students? Int J Med Educ. 2017;8:176-178.
44. Nishigawa K, Omoto K, Hayama R, et al. Comparison between flipped classroom and team-based learning in fixed prosthodontic education. J Prosthodont Res. 2017;61(2):217-222.

45. Anderson WL, Mitchell SM, Osgood MP. Comparison of student performance in cooperative learning and traditional lecture-based biochemistry classes. Biochem Mol Biol Educ. 2005;33(6):387-393. 46. Antepohl W, Herzig S. Problem-based learning versus lecturebased learning in a course of basic pharmacology: a controlled, randomized study. Med Educ. 1999;33(2):106-113. 